affect their health. Beyond this the state may wish to encourage better quality service and extend the range of activities that private doctors provide to include preventive programmes such as immunisation. These goals seem reasonable on paper but require a strong political commitment to ensure the accessibility of basic primary health services to the population and the existence of a clear vision of the minimum level of service that the state expects.

Invoking state regulatory mechanisms to improve the quality of the service provided is likely to be complex. The process will be contingent on existing regulation in the countries, the opportunities that may arise, and the strength of opposition to change. Regulating doctors' qualifications, their premises, and the care they provide is clearly a starting point. Control may also be achieved through resource management, such as social insurance schemes or payment of retainers or fees for service. Professional development and postgraduate training in primary health care could be a useful adjunct in improving quality. A reliance on training, however, assumes that the poor service results from inadequate professional knowledge rather than the perversity of market forces.

Private doctors' response to stronger state regulation, especially in countries where the private sector is well established, is likely to vary. State activity that interferes with their autonomy is likely to be unpopular. Collaborative change, with negotiation between professional groups and the state, may be the best way forward, but without strong government control it risks becoming little more than a tinkering with the existing system. Ensuring that private practitioners take on preventive activities and promote healthy behaviour by their patients requires a substantial move away from a strictly market led approach. Incentives and fees for service will be needed to reduce private doctors' autonomy and increase their accountability to the state. Yet this requires state money for health care.

Clearly, substantial changes are needed rather than tinkering. The goal of donor led initiatives should be to improve health care, not to increase private provision. ${ }^{10}$ Ironically, the international political changes that shifted the focus to private practice were also inimical to regulation and state funding of health care. The time seems ripe to change these guiding beliefs.

PAUL GARNER

Lecturer

Department of Public Health and Policy,

London School of Hygiene and Tropical Medicine, London WC1E 7HT

Community Health Sciences Department,

Aga Khan University,

Karachi, Pakistan

1 Bennett S. Private care in Third World needs regulating. BMf 1993;306:673-4.

a Peters DH, Becker S. Quality of care assessment of public and private outpatient clinics in Metro Cebu, Philippines. Intemational fournal of Health Planning and Management 1991;6:273-86.

Bhat R. The private health care sector in India: some policy concerns. Harvard: Takemi Programme in International Health, 1991. (International research paper No 54 .)

Ward P. Reproduction of social inequality: access to health services in Mexico City. Health Policy and Planning 1987;2:44-57.

World Bank. Financing health services in developing countries: an agenda for reform. Washington, DC: World Bank, 1987

World Health Organisation. The public/private mix in nationalhealth systems and the role of ministries of health. Report on an interregional meeting. Geneva: WHO, 1991.

6 Green A. The role of non-governmental organizations and the private sector in the provision of health care in developing countries. International fournal of Health Planning and Management 1987;2:37-58.

7 Bennett S. Promoting the private sector: a review of developing country trends. Health Policy and Planning 1992;7:97-110.

8 Uplekar M. Implications of prescribing patterns of private doctors in the treatment of tuberculosis in Bombay, India. Harvard: Takemi Programme in International Health, 1989. (International research paper No 41 .)

9 Greenhalgh T. Drug prescription and self medication in India: an exploratory survey. Soc Sci Med 1987;25:307-18.

10 Bennett S. The mystique of markets: public and private health care in developing countries. London: Department of Public Health and Policy, London School of Hygiene and Tropical Medicine, 199
Not often are authors of $B M \mathcal{F}$ papers arrested by the fraud squad, but this is what happened to the authors of the paper on $\mathrm{p} 691$. $^{1}$ They sent matched pairs of simulated curriculum vitaes - one bearing an English name and one an Asian name-in response to 23 advertisements for senior house officer posts. The only important difference between the curriculum vitaes was in the name, and yet the English names were significantly more likely to be shortlisted than the Asian names. Although the authors were charged by the fraud squad, they were not prosecuted.

We must always question the use of deception in research, but in this case the public and professional importance of the question being asked seems to justify the small element of deception. Ideally, the authors might before beginning the study have gained informed consent from the personnel departments of all the hospitals likely to be approached. This method has been used to gain consent from general practitioners for research in which they are consulted by surrogate patients. There would, however, have been at least two problems with using this method in the present study. Firstly, everybody likely to be a member of a selection panel would have had to give consent-a formidable logistic problem. Secondly, even a small proportion of people declining to give consent might have undermined the study- if those declining included most of those who knew that they allowed race to influence their judgments when shortlisting candidates for jobs.

The second crucial question is whether these results could have been obtained without deception. An expanding body of work does provide evidence of racial discrimination in medicine, ${ }^{2-6}$ and St George's Hospital Medical School was found to be using a computer program to shortlist applicants that downgraded those with non-English names. ${ }^{7}$ Nevertheless, most of this work is retrospective and there were other variables apart from racial differences. The present study was prospective and allowed only race to vary-and so adds important information.

Much research does include some deception. A placebo controlled trial does not present this problem because subjects give informed consent, but regularly in case-control studies subjects are not told the true reason for the study for fear that the study will be biased. Stooges are used increasingly in research on how general practitioners and pharmacists perform, and some famous studies have depended on substantial deception. Our thinking on mental hospitals has been strongly influenced by studies in which researchers pretended to be mentally ill, and in a television programme broadcast last week in Britain a reporter pretended to be homeless and 
schizophrenic to illustrate the bleak reality of being mentally ill and homeless ( $p$ 726). ${ }^{\text {7a }}$ The experiment in which people inflicted electric shocks on subjects who were actually actors is known to all psychology students, and even journalology has an important study that depended on deception: editors had papers that they had already published resubmitted to them with the titles and addresses changed and then rejected most of them-providing evidence, the researchers argued, that editors and referees were biased against authors from provincial universities. ${ }^{8}$

The study we publish today provides further evidence of racial discrimination in British medicine. Few doctors trained overseas will be surprised by the result. Many of them believe that the immigration of overseas doctors was encouraged to support the NHS in its early days, only for the overseas doctors subsequently to be marginalised. Australia has also seen debate over whether doctors trained overseas suffer racial discrimination. ${ }^{910}$ The demonstration of discrimination at St George's Hospital Medical School led to a flurry of reform, but a paper published in the $B M F$ in 1990 showed that doctors from ethnic minorities who had trained in Britain did not progress as fast in their careers as native European doctors. $^{2}$ The authors speculated that this discrimination occurred in shortlisting for senior house officer and registrar posts (rather than in interviews), and today's study supports that speculation.

The shortlisting problem can be countered by not letting those doing the shortlisting have access to the names, ages, and sex of the candidates, and this process should be adopted. But the problem of rooting racial discrimination out of the health service and medicine is a deeper one that needs a broad strategic approach. The Commission for Racial Equality has proposed such a strategy for primary care, ${ }^{11}$ and the NHS Management Executive has issued guidelines on equal opportunities in recruitment and selection procedures. ${ }^{12}$ These policies should be fully supported by doctors and their organisations-because racial discrimination damages both those discriminated against and those doing the discriminating. This damage has been powerfully illustrated in a famous study that depended on deception: John Howard Griffin, a white man, darkened his skin and trudged through the American south. In Black Like Me he writes: "I offer [my account] in all its crudity and rawness. It traces the changes which occur to heart and body when a so called first class citizen is cast on the junkheap of second class citizenship."13

\section{RICHARD SMITH}

Editor

$B M \mathcal{F}$

Esmail A, Everington S. Racial discrimination against doctors from ethnic minorities. $B M 9$ 1993;306:691-2.

2 McKeigue PM, Richards JDM, Richards P. Effects of discrimination by sex and race on the early careers of British medical graduates during 1981-7. BMF 1990;301:961-4.

3 Collier J, Burke A. Racial and sexual discrimination in the selection of students for London medical schools. Med Educ 1986;20:86-90.

Lewis G, Croft-Jeffreys C, David A. Are British psychiatrists racist? Br $\mathcal{F}$ Psychiatry 1990;157: 410-5.

5 King's Fund. The work of the equal opportunities task force 1986-90-a trial report. London: King's Fund, 1991.

6 Kingman S. Black students still underrepresented at UK medical schools. BMF 1992;304:1266.

7 Lowry S, Macpherson G. A blot on the profession. BMF 1988;296:657-8.

7a Persaud R. Home street home. BMF 1993;306:726.

8 Peters DP, Ceci SJ. Peer review practices of psychological journals: the fate of published articles submitted again. Behavioral and Brain Sciences 1982:5:187-95.

Gerber P. Overseas medical practitioners and "racial discrimination." Med f Aust 1991;155:509-12.

10 Moss I. Overseas medical practitioners and "racial discrimination." Med f Aust 1992;156:138.

11 Commission for Racial Equality, Race relations code of practice in primary health care services. London: CRE, 1992 .

2 NHS Management Executive. Equal opportunities in recruitment and selection procedures. London: NHSME, 1991.

13 Griffin JH. Black like me. London: Collins, 1962.

\section{All the homeless people-where do they all come from?}

\section{Probably not as many from psychiatric institutions as we think}

The coining of the term "cardboard city" reflects the public consciousness of the visible increase in the number of homeless people on our cities' streets. Because of problems of ascertainment, putting an accurate figure to this total is impossible. Using its restrictive definition of homelessness, the Department of the Environment estimates that the number of homeless families in England has more than doubled over the past decade to 146000 last year. (The housing charity Shelter says that this represents at least 420000 people.)

Many of these people are likely to have serious psychiatric problems. An early study of the Camberwell Reception Centre (now closed) found that one third of the residents were suffering from a severe psychiatric disorder, excluding alcoholism. ${ }^{1}$ Twenty years later, in a survey of men arriving at a Salvation Army hostel a quarter were diagnosed as having schizophrenia. ${ }^{2}$ During the intervening period surveys of homeless people in residential settings have estimated the prevalence of severe mental illness at between $25 \%$ and $45 \%$. While the proportion of mentally ill among homeless people has probably not changed greatly over the past two decades, the absolute number has probably doubled in parallel with the number of homeless people.

The number of occupied psychiatric beds in England has fallen from a peak of 148000 in $1954^{3}$ to about 45000 in 1992. Some commentators have ascribed the rise in the number of homeless mentally ill people to the run down of psychiatric hospitals and have called for a halt to the policy of closure. ${ }^{4}$ But have the erstwhile long stay patients swelled the ranks of homeless people? There are two sources of evidence bearing on this question: one is the psychiatric history of homeless mentally ill people, while the other is follow up studies of long term psychiatric patients discharged into the community.

Only a few of the surveys of homeless mentally ill people have inquired about any history of psychiatric treatment. A study of people using a shelter in Boston found that although 30 of the 68 respondents were suffering from a psychosis, only five had been admitted to hospital for longer than a year in total. ${ }^{5}$ A survey of 124 homeless men using a Salvation Army hostel found that over half were suffering from mental disorders but only seven had been admitted to hospital for longer than a year. ${ }^{2}$ In an experimental study of a case management service for homeless mentally ill people only two out of 94 people referred in a year reported having been admitted to hospital for a year or longer. ${ }^{6}$ During the first year of the London homeless mentally ill initiative 544 homeless people were identified as suffering from severe mental illness. Of these, only three had had a continuous hospital admission lasting more than five years. ${ }^{7}$

The follow up studies of discharged patients have produced complementary evidence. The Team for the Assessment of Psychiatric Services has been evaluating the run down of Friern and Claybury Hospitals in north London. A follow up of the 278 long stay patients discharged between 1985 and 